\title{
Oxidative Methods of Desulfurization Of Diesel Fuels \\ Results, Problems, Perspective
}

\author{
Akhmadova Kh.Kh. \\ Department of oil and gas chemical engineering \\ Grozny State Petroleum Technical University named after \\ M.D. Millionschikov \\ Grozny, Russia \\ hava9550@mail.ru \\ Khadisova Zh. T. \\ Department of oil and gas chemical engineering \\ Grozny State Petroleum Technical University named after \\ M.D. Millionschikov \\ Grozny, Russia \\ janna_h@list.ru \\ Krasnikov P.E. \\ Industrial ecology research centre \\ Samara State Technical University \\ Samara, Russia \\ krasnikovpe@gmail.com
}

\author{
Makhmudova L.SH. \\ Department of oil and gas chemical engineering \\ Grozny State Petroleum Technical University named after \\ M.D. Millionschikov \\ Grozny, Russia \\ mls66@mail.ru
}

Abdulmezhidova Z.A.

Department of oil and gas chemical engineering Grozny State Petroleum Technical University named after

\author{
M.D. Millionschikov \\ Grozny, Russia \\ zuli20@mail.ru
}

Idrisova E.U

Department of oil and gas chemical engineering Grozny State Petroleum Technical University named after M.D. Millionschikov Grozny, Russia idrisova999@mail.ru

\author{
Magomadova M.Kh. \\ Department of oil and gas chemical engineering \\ Grozny State Petroleum Technical University named after M.D. Millionschikov \\ Grozny, Russia \\ emina8383@mail.ru
}

\begin{abstract}
The article reveals the importance of the role of diesel fuel (DF) in Russian economy. In this regard, the quality of diesel fuel should meet European standards, according to which especially high requirements are imposed on the content of organic sulfur compounds in diesel fuel. It is shown that the intensification of the requirements for sulfur content in diesel fuel stimulates the search for new ways to clean it of sulfur compounds and improve the existing technologies of desulfurization processes. This article provides a brief overview of the methods for the desulfurization of diesel fuel. It is shown that one of the important methods for the improvement of the quality of diesel fuel is oxidative desulfurization. Due consideration is given to the various oxidative systems, catalysts and extraction agents used in oxidative desulfurization.
\end{abstract}

Keywords - diesel fuel, sulfur compound, oxidative desulfurization, oxidative systems, hydrogen peroxide, organic peroxides, organic acids, heterogeneous catalyst

\section{INTRODUCTION}

Nowadays there is a global tendency to increase the consumption of diesel fuel (DF) by an average of $4-5 \%$ per year, with simultaneous intensification of environmental requirements for its quality [1].

Diesel fuel, being one of the most popular motor fuels produced in the amount of up to $28-30 \%$ of the processed oil, plays an extremely important role in Russian economy.

In this regard, the quality of diesel fuel must meet European standards; especially high demands are imposed on the content of organic sulfur compounds in it $[2,3]$.

In order to reduce the harmful effect of sulfur on the environment and human, its content in diesel fuel is more and more strictly regulated every year health in many countries. Currently the permissible sulfur content is $10 \mathrm{ppm}$ [4] in most developed countries such as the USA, Japan and the EU. 
Since 2016 all diesel fuel in Russia is being produced in accordance with European standards.

In this regard, the main task in the production of diesel fuels is a significant improvement in their quality and, above all, the operational and environmental characteristics of both the fuels themselves and their combustion products $[1,5]$.

At present, more than $50 \%$ of diesel fuel produced in the country meets the requirements of Euro-3 standards (sulfur content is $0.035 \%$ or $350 \mathrm{ppm}$ ), Euro-4 (sulfur content is $0.005 \%$ or $50 \mathrm{ppm}$ ) and Euro-5 (sulfur content is $0.001 \%$ or 10 ppm) [6].

For the production of diesel fuels conforming to European standards, it is necessary to use new methods for desulfurization and the improvement of existing methods.

In the present research, the authors made an attempt to analyze the methods used for the oxidative desulfurization of DF and to show the effect of oxidizing agents, catalysts and organic acids on their intensification.

\section{The Dynamics Of Production And Export Of DF In RUSSIA}

The dynamics of the production of diesel fuel shows in average the following output by year: in $2010-70.0$ million tons, in $2011-70.6$ million tons $(27.5 \%)$, in $2012-69.7$ million tons $(26.3 \%)$, in $2013-72.0$ million tons $(26.4 \%)$, in 2014 - 77.3 million tons (26.8\%), in 2015 - 76.1 million tons $[5,6]$. By the end of 2015, the volume of production of diesel fuel in the Russian Federation decreased in comparison with 2014 by $1.6 \%$ [5]. By the end of 2015 , the volume of production of diesel fuel in the Russian Federation decreased compared to 2014 by $1.6 \%$ [5]. By the end of 2016, the production of diesel fuel is kept at the level of 2015 and amounted to 76, 1 million tons [7].

Diesel fuel in Russia is produced approximately twice as much as is needed for national consumption, and half of the volume produced is exported.

According to the long-term forecast of the Ministry of Energy of the Russian Federation, the dynamics of production and consumption of diesel fuel will increase. Thus, according to the forecast, by 2020, diesel fuel production in Russia will increase up to 100 million tons, and national consumption will increase up to 50 million tons. It is assumed that the balance of exports and national consumption in the long term will remain the same.

The export of diesel fuel reaches an average of $50 \%$ of its total production [5]. Thus, in 2012, 33.6 million tons $(51.5 \%$ of its production) were exported, in $2013-43.0$ million tons (59.7\%), in 2014 - 50.3 million tons $(65.07 \%)$ [8]. The indicators of national consumption and export of diesel fuel in the Russian Federation in 2015 showed the decline of $2.2 \%$ and $0.9 \%$, respectively, to 31 and 45 million tons.

DF, being in the structure of Russian exports in third place after oil and gas, ensures the flow of significant international currency into the country. The income from the export of diesel fuel in Russia is constantly growing. For example, according to the FAS, the revenue from the export of petroleum products from Russia in 2012 increased by $12 \%$, and this positive trend was achieved mainly due to diesel fuel: revenues from diesel fuel exports increased by $16 \%$, while revenues from exports gasoline decreased by $4 \%$ [9].

The buyers of Russian diesel fuel traditionally are the countries of Western Europe and the Mediterranean region. High-sulfur national diesel fuel exported to the EU market does not meet environmental requirements. It is a very profitable raw material for refining in European countries that produce from it an ultra-low-sulfur product that is in demand on the European market [10]

Russian sulfurous diesel fuel in the Western European markets was sold until 2016 at the price of raw materials (vacuum gas oil). European refineries that process imported diesel fuel from Russia brought it to European standards and sold at intra-European prices, receiving significant profits. From 2016, all diesel fuel in Russia began to be produced in accordance with European standards, and therefore it enters European markets at prices prevailing in these markets, which leads to fierce competition with local diesel fuel, as well as with products imported from the United States, Saudi Arabia and India [10].

\section{The Tendencies Of The Development Of DF PRODUCTION}

The solution of the problems associated with the production and use of high-quality diesel fuel in the Russian Federation, is extremely relevant now.

In the oil refining industry of the Russian Federation, the following development trends have been traced for a long time, influencing the process of diesel fuel production.

Firstly, there high demands are imposed on the performance characteristics of fuels, which consist in the improvement of the starting properties of engines, its service life, and the reduction of fuel consumption. The restrictions on density and viscosity, as well as new indicators of lubricity and oxidative stability have been introduced.

According to the Euro- 4 standard and in order to meet these requirements, the lower limit of the cetane number is limited to not less than $51 \mathrm{p}$., while the engine operates in favorable "soft" conditions: its power and economic indicators increase. The use of diesel fuel with a cetane number below 50 units leads to "hard" operation of an engine; there are shock loads on a piston, bearing wear increases and deformation the piston rings, a breakthrough into the crankcase of exhaust gases.

Secondly, the strict limits of applicability of fuels for environmental performance are established. The content of those compounds that, during the combustion process, form carcinogens that are harmful to both the environment and humans is limited.

Thirdly, the permissible total sulfur content in diesel fuel is significantly reduced from 0.5 to $0.035 \%$. The content of polycyclic aromatic hydrocarbons is regulated, up to not more than $11 \%$. 
The presence of sulfur reduces the performance of fuels and oils, causes corrosion of equipment, reduces the activity of anti-knock and antioxidant stability of fuel, and leads to air pollution in cities $[2,11]$.

The sulfur content in straight-run fraction of diesel fuel produced at crude oil distillation units exceeds $5000 \mathrm{ppm}$, and in accordance with European standards it is necessary to bring the content of sulfur to 50-10 ppm [12].

Accordingly, the current requirements of such deep fuel desulfurization cause a number of technical problems in national refining industry.

In Russia, oil companies is making efforts aimed at the massive transition of national refineries to the production of environmentally friendly diesel fuel with a sulfur content of no more than $0.035 \%$ and $0.005 \%$ and polycyclic aromatic hydrocarbons no more than $11 \%$ [1].

As it was mentioned above, more than a half of diesel fuel produced in the country meets the requirements of Euro-3 standards (350 ppm sulfur content), Euro-4 (50 ppm sulfur content) and Euro-5 (10 ppm sulfur content) [6].

\section{SULFUR COMPOUND IN DF}

The diesel fractions contain various sulfur compounds: mercaptans, sulfides, disulfides, as well as thiophene, benzothiophene (BT), dibenzothiophene (DBT) and their alkylated derivatives, polycyclic sulfur compounds containing 3 or more cycles (benzonaphthiophene), phenanthro [4,5 bcd] thiophene and its alkylated derivatives [2-4, 11-17]. Sulfur included in the thiophene fragment usually composes $50-95 \%$ of the total sulfur content in crude oil $[2,3]$.

The main sulfur compounds that must be removed from diesel fuel in order to reduce their sulfur content from 300-500 ppm to the required level of Euro-3, 4 and 5 are represented mainly by benzothiophene, dibenzothiophene, and their alkyl derivatives [4, 13-15]. Dibenzothiophene and alkoxylated derivatives account for up to $70 \%$ of sulfur in DT [3].

The articles $[13,16]$ investigated the composition and structure of sulfur compounds of diesel fractions and determined their relative reactivity in the process of hydrodesulphurization.

The structure of the main sulfur compounds contained in diesel fraction is given in Table 1 [17]. In general, sulfur compounds of diesel fractions are conventionally divided into three groups $[18,19]$ :

- easily-hydrating compounds - a mixture of aliphatic and cyclic sulphides;

- mid-hydrating compounds - homologues of thiophene and benzothiophene;

- hardly-hydrating compounds - derivatives of dibenzothiophene.
TABLE I. THE STRUCTURE OF SULFUR-CONTAINING COMPOUNDS OF DIESEL FUEL

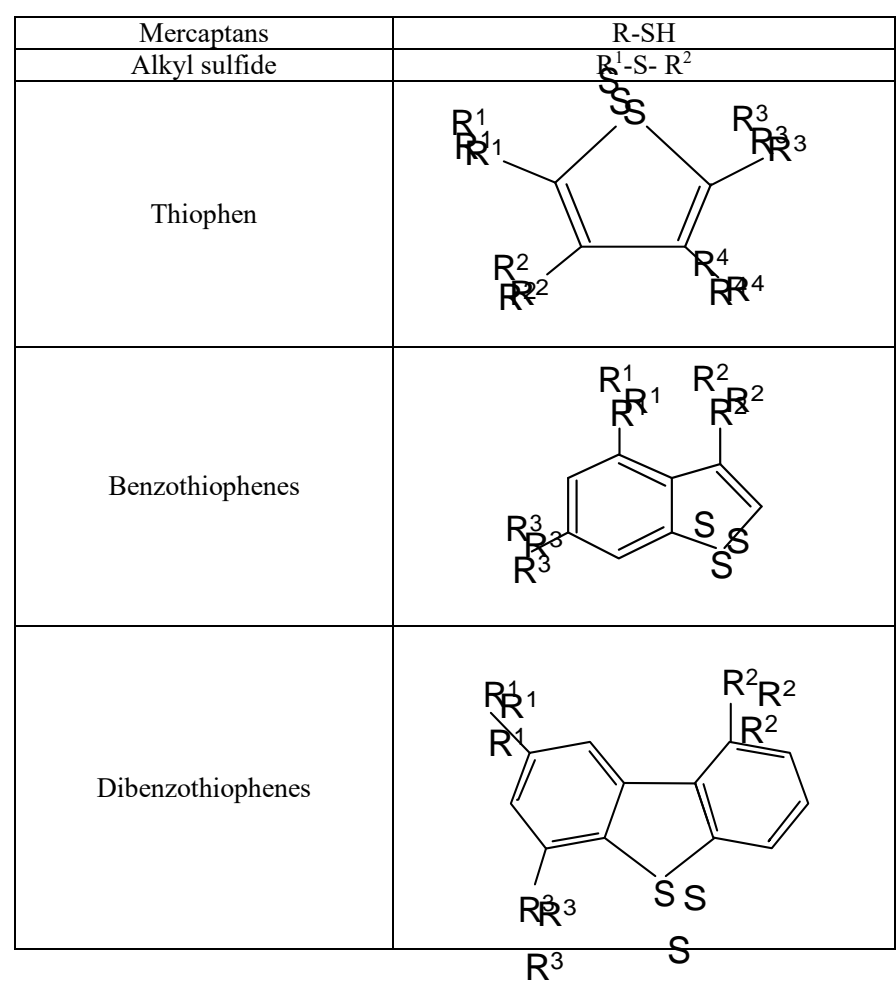

The authors of the article [16] showed that these compounds, having different activity, are concentrated in different DF fractions: lightly mercaptans and sulfides are distributed relatively evenly, thiocyclans are concentrated in head fractions, benzothiophenes are presented in tailings.

The work [20] shows that in diesel fuels with a sulfur content of $0.6 ; 1$ and $1.7 \%$ of the mass, such compounds as benzothiophenes dominate.

The authors of this study [20] found that with the increase in sulfur content from 0.6 to $1.7 \%$ by weight, the concentration of lightly cracked sulfur compounds decreased from 46 to $38 \%$, and the average cracked compounds increased from 46 to $54 \%$. The concentration of dibenzothiophenes derivatives in all samples was almost the same. A study of the C-S bond hydrogenolysis rate of various groups of compounds showed that the rate decreased in the following order:

thiophenes $>$ benzothiophenes $>$ dibenzothiophenes.

In the production of diesel fuel with a sulfur content of not more than $0.05 \%$ by mass, the conversion of thiophene derivatives reached $94 \%$, benzothiophene - $88 \%$, and dibenzothiophene $-80 \%$. The analysis of the content of sulfur compounds by fractions showed that during the transition to heavier fractions, the content of sulfides decreased and an increase in the concentration of thiophene derivatives was observed [20].

During the investigation of the distribution of sulfur compounds in the narrow fractions of diesel fuel in $[13,18$, 20] it was found that sulfur-containing compounds are 
distributed unevenly in them, depending on the nature of the oil and the type of sulfur compounds.

For example, in aromatic compounds of the $220-3000^{\circ} \mathrm{C}$ of DF fraction, mainly $\mathrm{C} 2-\mathrm{C} 5$ substituted benzothiophenes and dibenzothiophenes were present, and in the fraction above $3000^{\circ} \mathrm{C}$, C5-C6 substituted benzothiophenes, dibenzothiophenes, 4-methyldibenzothiophenes and dimethylbenzothiophenes $[18,20]$ were present.

In the research [21] it was found that the introduction of a methyl substituent into dibenzothiophene reduced the degree of hydrodesulphurization of the hydrocarbon fraction by $30 \%$, and the introduction of two methyl substituents - up to $80 \%$.

Most of the existing methods for the removal of organic sulfur compounds are based on their destruction before hydrogen sulfide or removal as waste $[1,22]$.

\section{The Methods Of DF DesulphuRIZATION}

The most widely used for the production of diesel fuels that meet modern operational and environmental requirements are currently the following industrial methods: catalytic, hydrogenation (hydrotreating, demercaptanization) and methods based on the use of various additives; various methods of cleaning diesel fuels (extraction and adsorption) $[1-4,12,17-31]$.

These methods are based on methods of the removing of sulfur from raw materials by destroying sulfur compounds and removing them from raw materials (hydrotreating, biodesulfurization) and isolating organic sulfur compounds and simultaneously cleaning the raw materials (extraction, adsorption) [4, 11-13, 17-29].

The purpose of sulfur removal from diesel fuels are environmental and technological reasons related to the reduction of sulfur oxide emissions resulting from the combustion of sulfur compounds into the atmosphere and the improvement of the quality of commercial diesel fuels. Sulfur also needs to be removed, since it leads to the deactivation of catalysts for the hydrotreating processes of diesel fuel, being a poison for them [13, 17, 21-23].

The main industrial methods for desulphurization of crude oil are hydrogenation processes, including a combination of catalytic refining processes such as hydrodesulphurization, hydrodeazotization, hydrodemetallization $[1,8,11,1 \& 21,22$
$30-32]$.

Hydrodesulphurization is the most widely used industrial method for the removal of sulfur from DF. Homere des inite the fact that the current hydro-processing is widely used and are the main desulfurization processes, they have a number of significant drawbacks such as intensified operating comitiofins, high operating costs for the process and the absence of the ability to meet all the intensified environmental standards for sulfur 4, 8].

The intensification of the requirements for sulfur content in motor fuels stimulates the search for new ways to clean hydrocarbon feedstock from sulfur compdunds and the improvement of existing technologies for desulfurization processes [4, 8, 17, 33]. The search for new, unconventional methods for removing sulfur from motor fuels is acquiring particular urgency.

These technologies are represented by the following processes: oxidative desulfurization, biological methods, ozonolysis, unconventional methods of processing raw materials and the resulting fuels (magnetic, ultrasonic and other wave effects) or a combination of these methods $[4,17$, $31,32]$.

\section{OXIDATIVE DESULFURIZATION OF DF}

Oxidative desulfurization is based on the modification of functional groups of sulfur compounds and has long been used in oil refining in order to remove sulfur compounds due to the simplicity of the process of separating oxidized oil compounds from hydrocarbons [4, 13, 14, 17]. One of the first known methods for the oxidation of sulfur compounds is the method of sulfuric acid cleaning. Concentrated sulfuric acid, being a strong oxidizing agent, oxidizes mercaptans to disulfides, sulfides to sulfoxides, thiophanes and thiophenes to sulfoxides. The prospect of the oxidation method is reasoned by the possibility of practical use of the resulting sulfoxides and sulfones.

Over the past decade, the methods of oxidative desulfurization have progressed greatly, and many research papers have been devoted to this issue, including a number of reviews by national and international authors [4, 24-36].

These works review oxidative systems and catalysts used for the desulphurization of petroleum feedstock, as well as the problems which researchers face. Many articles related to oxidative desulfurization indicate a significant interest of researchers to this issue [4,13,14,17,23-101].

Schematically, the process of oxidative desulfurization can be represented in two stages: the oxidation of sulfur compounds and the removal of the formed sulfur compounds by extraction, adsorption, or other methods [17].

The first stage of the process is the oxidation of sulfur compounds in order to change the functional groups. Sulfides are oxidized with the highest rate, turning into a mixture of sulfoxides and sulfones (Fig. 1).

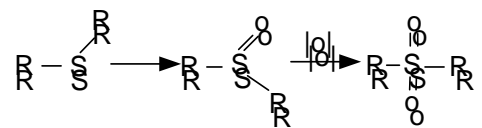

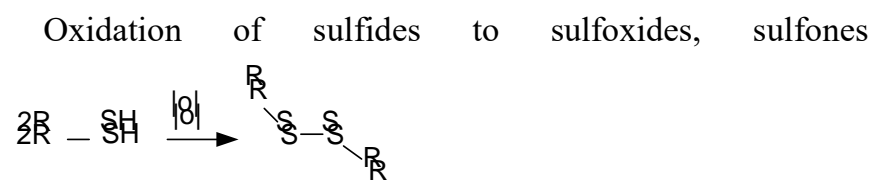

Oxidation of mercap
$\S$ 


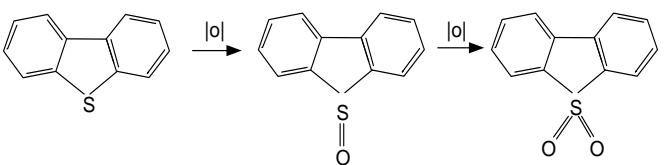

Fig. 1. Oxidation of sulfur components of crude oil - Oxidation of dibenzothiophene to sulfoxide and sulfone

The study of selective oxidation of petroleum sulphides with hydrogen peroxide into sulfoxides and sulfones is described in the work [29].

With a slightly lower rate, mercaptans are oxidized to disulfides and polycyclic thiophenes to sulfones.

Further oxidation can lead to the formation of watersoluble products - alkanesulfonic acids and, finally, sulfuric acid [23, 30, 31].

Sulfoxides and sulfones have two properties that distinguish them from the original sulfur compounds and facilitate desulfurization. Firstly, they are more polar in nature, which increases the selectivity of extraction with polar solvents, despite the fact that this property does not reduce solvent losses and the cost of solvent regeneration. Secondly, the $\mathrm{C}-\mathrm{S}$ connection becomes less durable when the sulfur atom is oxidized; therefore, it is easier to remove it by temperature treatment.

\section{BASIC OXIDATIVE SYSTEMS For THE DESULFURIZATION OF DF}

The most common oxidizing agents of organic sulfur compounds include hydrogen peroxide [31, 32-34] and organic hydroperoxides $[35,36]$ : alkyl hydroperoxides, cyclohexanone peroxide, tert-butyl hydroperoxide, tert-butyl hydroperoxide, etc. The extractants of sulfoxides removal and sulfonic nitrate are distilled acetone solution [35].

Peroxocomplexes of transition metals are more effective oxidizing agents than hydrogen peroxide; therefore, the reactions catalyzed by them are becoming increasingly important. Peroxocomplexes can be obtained directly in the reaction mixture by adding hydrogen peroxide to the solution of the salt of the transition metal in the highest oxidation state [37].

\section{A. Hydrogen peroxide}

Currently The most widely used and most common oxidizing agent for the conversion of sulfur compounds of petroleum fractions, including diesel fractions, is hydrogen peroxide (H2O2) [4, 13, 17, 23, 62], which, depending on the quality of raw materials and content in it, sulfur can be used in combination with various catalysts (organic acids, metals, redox catalysts, Fenton catalysts), hydrocarbons and solvents [4, 13, 17, 23, 29-45, 50-77].

For oxidative desulfurization of diesel fuel, a system of hydrogen peroxide and an acidic catalyst: formic or acetic acid is successfully used [4, 13, 17, 23, 29-48].

Also recently, a large number of systems using hydrogen peroxide as an oxidizing agent and various catalysts have been proposed: titanium-containing zeolites, mesoporous titaniumcontaining catalysts, vanadium-containing molecular sieves, molybdenum-containing molecular sieves placed on different carriers $[4,13,14,17,31,33$ - 45, 50 -77].

One of the alternative methods for the removing of sulfur from petroleum feedstock is oxidative desulfurization using a complex of hydrogen peroxide with Fenton-catalyst (ferric chloride (II), copper sulfate) [4, 37].

In the research [4, 39], it was shown that during the oxidation of diesel fraction of Arlan oil with a sulfur content of $2.2 \%$ by weight in order to obtain sulfoxide concentrates, an oxidizing agent is used in the form of a $30 \%$ aqueous solution of hydrogen peroxide.

For the oxidation of alkyl aromatic sulfides to the corresponding sulfoxides and sulfones, hydrogen peroxide is used, which forms peroxocomplexes with transition metal salts, for example, vanadium [40] or niobium [41].

One of the main advantages of the use of hydrogen peroxide is environmental safety, since the only side effect product of its use is water $[42,17]$.

The efficiency of using hydrogen peroxide in the desulfurization of diesel fuels is significantly increased in the presence of various catalysts, hydrocarbons and solvents [4345]. Systems with organic acids and heterogeneous catalysts are most frequently used with hydrogen peroxide [50-52].

\section{B. Oxidizing systems of hydrogen peroxide and organic acids}

The use of an acid catalyst in the oxidation of sulfur compounds with hydrogen peroxide leads to a chemical reaction, during which peroxide compounds or peracids are formed. Organic peracids are very strong oxidizing agents and are capable of oxidizing sulfur compounds, providing $21.1 \%$ of active oxygen [43].

Such compounds are reactive and at the same time corrosive, for this reason their synthesis occurs using hydrogen peroxide and carboxylic acid, usually acetic or formic [44-45]:

\section{$\mathrm{RCOOH}+\mathrm{H}_{2} \mathrm{O}_{2} \rightarrow \mathrm{RCOOOH}+\mathrm{H}_{2} \mathrm{O}$}

Reactivity of sulfur-containing compounds, including methylphenylsulfide, thiophenol, diphenyl sulfide, 4methyldibenzothiophene (4MDBT), difenzothiophene (DBT), benzothiophene (BT), 2-methylthiophene (2-MT), 2.5dimethylthiophene (2.5-DMT) thiophene, with respect to the oxidation of the system $\mathrm{H} 2 \mathrm{O} 2$ / formic acid was investigated in the research [46].

Carrying out the oxidation at $50^{\circ} \mathrm{C}$ and atmospheric pressure ensures the removal of sulfur in the fuel to $92 \%$. Formic acid has a greater effect on the oxidation process than hydrochloric and acetic acid. The combination of oxidation and extraction reduces the sulfur content in diesel fuel at $50^{\circ}$ $\mathrm{C}$ and atmospheric pressure by an order of magnitude: from 1044 to $100 \mathrm{ppm}$, the degree of sulfur removal is $92 \%$.

In research work [47], it is proposed to use hydrogen peroxide in the presence of formic acid in various solvents in order to oxidize sulfur compounds of diesel fuel. 
In research work [48], for the oxidative desulfurization of diesel fuel, a system of hydrogen peroxide and an acidic catalyst, formic or acetic acid, was successfully used, followed by extraction of the oxidation products with acetonitrile.

The oxidative system of hydrogen peroxide and acetic acid, along with formic acid, is also successfully used in oxidative desulfurization. This system was first proposed by national researchers for the selective oxidation of oil sulphides to sulfoxides in 1976 [49].

The use of acetic and formic acids requires a large amount of an oxidizing agent; therefore, catalysts, mainly transition metal salts and tungsten salts, are often used to intensify the process [50-52].

Oxidation reactions of sulfur compounds in the presence of $\mathrm{H} 2 \mathrm{O} 2$ can occur both under homogeneous and heterogeneous catalysis.

In research work [53], it was found that the oxidative system of $\mathrm{Na} 2 \mathrm{WO} 4, \quad 30 \% \mathrm{H} 2 \mathrm{O} 2$ and acetic acid is successfully used for the desulfurization of diesel fuel in twophase conditions. In the model sample of diesel fuel containing dibenzothiophene and 4,6dimethyldibenzothiophene, the total sulfur content at $70^{\circ} \mathrm{C}$ in less than 1 hour decreased from 1100 to $40 \mathrm{ppm}$.

In research work [50], phosphorotungstic acid was used as an oxidation catalyst in a two-phase light gas oil / H2O2 / formic acid system.

It was shown in the work [49] that the use of an excess of hydrogen peroxide in the presence of phosphoromolybdic acid during the process of desulfurization of diesel fuel with a sulfur content of $342 \mathrm{ppm}$ results in $100 \%$ desulfurization in 3 hours at $60^{\circ} \mathrm{C}$.

\section{Heterogeneous systems - peroxide oxidizers and heterogeneous catalysts}

As it was mentioned above, the oxidation reactions of sulfur compounds are carried out not only under conditions of homogeneous catalysis, but also under conditions of heterogeneous catalysis.

Heterogeneous systems consisting of peroxide oxidizing agents (hydrogen peroxide or alkyl hydroperoxide) and from a variety of solid carriers, such as salts, oxides, activated carbon, zeolites, etc. are also widely used in order to remove sulfur compounds from diesel fuel [47].

The examples of the use of these systems are the oxidation of model sulfur compounds of diesel fuel with hydrogen peroxide on a vanadium catalyst [4].

Various manganous oxides, $\mathrm{Mn3O} 4, \mathrm{Mn} 2 \mathrm{O} 3$ and $\mathrm{MnO} 2$ show good results in the oxidation of DF sulfur compounds, regardless of the concentration of hydrogen peroxide; placed vanadium catalysts V2O5 / $\mathrm{Al} 2 \mathrm{O} 3$ and V2O5 / TiO2 [54]; TS1 titanium silicate catalyst, which is presented by packaged nanocrystals [55].

In research work [32], it is proposed to use hydrogen peroxide in the presence of metal compounds (Mo, V, W) for the oxidation of sulfur compounds of diesel fuel. Oxidation with hydrogen peroxide was carried out in the foam emulsion mode in the presence of metal compounds (Mo, V, W) followed by catalytic decomposition of sulfones into sulfur dioxide and hydrocarbon [4, 17].

Manganese and cobalt oxides placed on $\mathrm{Al} 2 \mathrm{O} 3$ catalyze air oxidation of sulfur compounds present in diesel fuel at 130 $200^{\circ} \mathrm{C}$ and atmospheric pressure [56]. During the subsequent extraction of oxidation products with a polar solvent, the sulfur content in diesel fuel decreases to $40-60 \mathrm{ppm}$. The use of hydrogen peroxide as an oxidizing agent makes it possible to conduct desulfurization and extraction simultaneously.

Molybdenum-containing catalysts present one of the most effective heterogeneous systems for the oxidative desulfurization of diesel fuel [51].

For example, a high degree of sulfur removal up to $98 \%$ is achieved under mild conditions by the action of hydrogen peroxide in the presence of polymolybdates placed on $\mathrm{Al} 2 \mathrm{O} 3$ [57].

The research work [58] proposed a variant of oxidative desulfurization using hydrogen peroxide without using a phase transfer catalyst and organic acids with a $100 \%$ result of removing dibenzothiophene from the model mixture under mild process conditions for 2 hours. The use of catalyst $\mathrm{AlPMo}_{12} \mathrm{O}_{40}$ for the process of oxidative desulfurization of model fuel made it possible to reduce the sulfur content from $1000 \mathrm{ppm}$ to $1 \mathrm{ppm}$.

Molybdenum peroxocomplexes exhibited high activity in the oxidation of sulfides of the diesel fraction of oil with $30 \%$ hydrogen peroxide, containing in the coordination sphere as ligands for a two-molecule sulfoxide [59, 60].

The maximum degree of conversion of sulphides to sulfoxides was $78 \%$, when naphthenate-molybdenum was used as a source of metal. The disadvantage of this method is the irreversible loss of the catalyst as a result of its partial dissolution in organic phase [4].

In research work [58], several polyoxometalates Na2HPM12O40, H3PM12O40, Na2HPM12O40, (VO) H [PM12O40] and (n-Bu4N) 3 [PM12O40] (M = MoandW), and also $(\mathrm{n}-\mathrm{Bu} 4 \mathrm{~N}) 3+\mathrm{x}$ [PW12 $-\mathrm{xVxO} 40](\mathrm{x}=0-3)$ were synthesized and used as a catalyst for the oxidation process in the $\mathrm{H} 2 \mathrm{O} 2$ / acetic acid system. The results showed that tungsten-containing catalysts are more active than molybdenum-containing catalysts.

The effective catalysts for the oxidative desulfurization of diesel fuel are titanium-containing catalysts: a TS-1 titanium silicate catalyst, which is presented by packaged nanocrystals [61]; $0.06 \%$ Ag / TS-1 prepared by the impregnation method [4.66]; titanium-containing catalyst Ti / HMS, which exhibits high activity in the oxidation of dimethylbenzothiophene [63].

Solid acid catalysts and / or activated carbon are also used as heterogeneous catalysts for oxidative desulfurization. The acid catalyst is usually chosen from the following group of compounds: zirconium sulphate, aluminum sulphate, sulphated tin oxide, iron oxide, zirconium molybdate and oxideol molybdate [64]. 
Systems of metal ions and aldehydes are also effective in the oxidative desulfurization of air with oxygen by diesel $[65$, $66]$.

In research work [67] for the oxidation of dibenzothiophene, 4-methyldibenzothiophene and 4,6dimethyldibenzothiophene a mixture of isobutyraldehyde / oxygen of a non-metallic catalyst was used. The effectiveness of this system in combination with extraction with a polar solvent was demonstrated by the example of oxidative desulfurization of diesel fuel with a sulfur content of $448 \mathrm{ppm}$. In this way, in a two-phase system, the sulfur content was reduced to $77 \mathrm{ppm}$, and after passing the sample of oxidized fuel through a column with silica gel, the sulfur content in it was reduced to $31 \mathrm{ppm}$.

In research work [68], it was shown that the use of amphiphilic catalysts of the surfactant type, which promote the formation of a water / oil emulsion, leads to the increase in mass transfer in the reactor during oxidative desulfurization of diesel fuel.

In research studies $[69,70]$ it was found that a high degree of purification of diesel fuel from sulfur compounds can be achieved under mild conditions in an emulsion system water in oil composed of a diesel fraction, $30 \%$ hydrogen peroxide and an electrophilic catalyst $\left[\mathrm{C}_{18} \mathrm{H}_{37} \mathrm{~N}\left(\mathrm{CH}_{3}\right)_{3}\right]_{4}$ $\left[\mathrm{H}_{2} \mathrm{NaPW}_{10} \mathrm{O}_{36}\right]$. Using this method in combination with extraction, the sulfur content in diesel fuel was reduced from 500 to $1 \mathrm{ppm}$, and in straight-run gas oil from 312 to $1 \mathrm{ppm}$. In this case, the amphiphilic component serves not only as an oxidation catalyst, but as an emulsifier that stabilizes emulsion droplets [71].

In the study [72], the catalyst $\left[\left(\mathrm{C}_{18} \mathrm{H}_{37}\right)_{2} \mathrm{~N}\right.$ $\left.\left(\mathrm{CH}_{3}\right)_{2}\right]_{3}\left[\mathrm{PW}_{12} \mathrm{O}_{40}\right]$ is used for the selective oxidation of sulfur components of diesel fuel without the use of a phase transfer catalyst. Metastable emulsion droplets, which are formed after the catalyst is introduced into the water / oil system, act as a homogeneous catalyst. The catalyst has a high catalytic activity with respect to 4,6-DMDBT (4,6dimethyldibenzothiophene) even at room temperature and can be removed from the system by centrifugation. The catalyst $\left[\left(\mathrm{C}_{18} \mathrm{H}_{37}\right)_{2} \mathrm{~N}\left(\mathrm{CH}_{3}\right)_{2}\right]_{3}\left[\mathrm{PW}_{12} \mathrm{O}_{36}\right]$ developed by the same group of researchers, is presented in [73]. Using this catalyst, researchers have shown that even heavily oxidized BT (benzothiophene) is oxidized to the corresponding sulfone in an emulsion medium.

Quaternary salts of ammonium bases, such as [(C4H9) 4NRCOOO], consisting of the oxidation anion [RCOOO] and ammonium salt cation [74], are used as a phase transfer catalyst in water / oil systems for oxidative desulfurization.

In the work [75], tetraoctylammonium bromide, hydrogen peroxide as an oxidizing agent, and phosphorofenomethyl acid as a catalyst were used as interfacial transfer catalysts in order to improve mass transfer processes in oxidative desulfurization of diesel fuel.

The use of a complex from tetraoctylammonium bromide and a stabilizing emulsion of amphiphilic phosphorofungmic acid made it possible to remove up to $98 \%$ of sulfur from commercial diesel fuel [76].
For the oxidation of alkylaromatic sulfides to the corresponding sulfoxides and sulfones, hydrogen peroxide can be used, forming peroxocomplexes with transition metal salts, for example, vanadium or niobium [4].

The reaction takes is performed in a two-phase system with high yields, the oxidizing agent is in the aqueous phase, and the substrate is in the organic phase.

\section{Activated carbon in the process of oxidative desulfurization}

Activated carbon is one of the common carriers for heterogeneous oxidative desulfurization [76, 78]. Its use provides the oxidative desulfurization of diesel fuel by the action of hydrogen peroxide [78].

Modified activated carbon is also a catalyst for the oxidation of thiophenic compounds; in the presence of active carbon, more sulfur is removed with carboxyl groups (>95\%) than without it $(60 \%)$ [17]. Activated carbon has a high catalytic activity and can be easily regenerated by simple water washing without significant loss of activity after three cycles of regeneration.

The higher the adsorption capacity of activated carbon, the higher its activity in the oxidation of sulfur compounds. The addition of formic acid accelerates the oxidation process. The use of such a system allows reducing the sulfur content in diesel fuel from 800 to $142 \mathrm{ppm}$. Additional adsorption treatment of diesel fuel with activated carbon lowers its sulfur content to $16 \mathrm{ppm}$.

In the study [79], the authors showed that activated carbon for the oxidative desulfurization of diesel fuel with hydrogen peroxide removes $98 \%$ of sulfur with losses not exceeding $3.5 \%$.

\section{E. The combination of oxidative desulfurization with adsorption and extraction with polar solvent}

The efficiency of oxidative desulfurization of hydrocarbon fuels increases significantly when adsorption of product oxidation on a solid adsorbent follows the oxidation process.

The combination of oxidation with adsorption on $\mathrm{Al}_{2} \mathrm{O}_{3}$ or $\mathrm{SiO}_{2}$ and extraction with a polar solvent makes it possible to achieve the degree of sulfur removal from diesel fuel of more than $97 \%$ [4].

In the work [76], as it was shown above, when extracting oxidation products obtained on manganese and cobalt oxides placed on $\mathrm{Al}_{2} \mathrm{O}_{3}$ with a polar solvent, the sulfur content in diesel fuel decreases to $40-60 \mathrm{ppm}$.

In the work [77], the use of silica gel for the adsorption of oxidation products of once-run diesel fraction and gas oil catalytic and thermal cracking with hydrogen peroxide in the presence of compound of oil and acetic acid allowed reducing the sulfur content in the fuel from $482 \mathrm{ppm}$ to $50 \mathrm{ppm}$.

The combination of peroxide oxidation of sulfur compounds in motor fuels in the presence of heterogeneous carriers with subsequent adsorption removal of oxidation 
products is also described in a number of patent works [82, 83].

The effectiveness of oxidative desulfurization, which is presented by the combination of catalytic oxidation of sulfur compounds with molecular oxygen in the presence of a heterogeneous catalyst and adsorption on activated carbon under mild conditions $\left(25^{\circ} \mathrm{C}\right)$, was also demonstrated in the research [84].

\section{F. Oxidative desulfurization with organic peroxides}

Another group of oxidizers used in the oxidative desulfurization of diesel fuel is organic peroxides, which, as well as hydrogen peroxide, are used in combination with catalysts, such as Mo-containing [85].

The most widely used peroxide is tert-butyl hydroperoxide, which is used as a selective oxidant of various organosulfur compounds (methylphenylsulfide, diphenylsulfide, 4-methyldibenzothiophene, 2,5dimethylthiophene) on CoAPO--5 heterogeneous catalysts (APO-aluminophosphate, $\mathrm{Cu} / \mathrm{Al}=0,15$ ) and $15 \% \mathrm{MoO}_{3} / \mathrm{Al}_{2} \mathrm{O}_{3}$ [86].

The rate of oxidation of the sulfur compound is substantially higher on cobalt rather than on the molybdenum catalyst.

During the oxidation of benzothiophene, dibenzothiophene, 4-methyldibenzothiophene and 4, 6dimethyldibenzothiophene, the action of tert-butyl hydroperoxide on $\mathrm{Mo} / \mathrm{Al}_{2} \mathrm{O}_{3}$, the catalyst with $16 \%$ molybdenum content showed the highest activity in the oxidation of dibenzothiophene; the further increase in the metal content in the catalyst reduced its catalytic activity [87].

According to the reactivity during oxidation on the catalyst $16 \% \mathrm{Mo} / \mathrm{Al}_{2} \mathrm{O}_{3}$ the sulfur compounds are arranged in a row: dibenzothiophene $>$ 4-methyldibenzothiophene $>$ 4,6-dimethyldibenzothiophene $>$ benzothiophene.

For dialkyl derivatives of benzothiophenes, desulfurization proceeds most easily on the $\mathrm{CoMo} / \mathrm{Al}_{2} \mathrm{O}_{3}$ catalyst [4].

The various oxidation systems have been proposed for the oxidation of dibenzothiophene and its mono- and dialkyl derivatives, and the position of alkyl groups in dialkyl benzothiophenes plays an important role in their reactivity [4].

As early as in 1971 the use of tert-butyl hydroperoxide as an oxidizing agent in the process of oxidative desulfurization of oil in the presence of vanadium acetylacetonate at $90^{\circ} \mathrm{C}$ was mentioned.

The conversion of sulfur compounds in this process reached $74 \%$ [88]. The same result was obtained using hydrogen peroxide at $400-415^{\circ} \mathrm{C}$ and a pressure of $60 \mathrm{~atm}$ in studies conducted later in 1972-1973 [89, 90].

The increase in the catalytic activity of molybdenumcontaining catalyst by calcination with $10 \%$ ferrum $(\mathrm{Fe})$ was described in the research [91].
The use of $\mathrm{Fe}-\mathrm{MoO}_{3} / \mathrm{Al}_{2} \mathrm{O}_{3}$ catalyst calcined at $550{ }^{\circ} \mathrm{C}$ made it possible to reduce the content of organic sulfur compounds in diesel fuel from 440 to $88 \mathrm{ppm}$ [17].

A number of papers have described the use of phosphoruswolframic acid as an effective catalyst for the oxidation of sulfur compounds by tert-butyl hydroperoxide [92, 93].

The main advantage of tert-butyl hydroperoxide is its solubility in the hydrocarbon phase, which avoids the formation of a two-phase system, as in the case of hydrogen peroxide.

However, the tert-butyl hydroperoxide is more expensive than hydrogen peroxide, which makes it less economically advantageous as an oxidizing agent [17].

The results of these studies show that the method of oxidative desulfurization is very effective and many researchers recommend using it as an addition to hydrotreatment for the most complete removal of sulfur.

Comparing the efficiency of hydro-treating and oxidative desulfurization processes, the authors note the advantage of the last approach: much milder conditions and greater reactivity to oxidation of diesel fractions $[4,17]$.

\section{CONCLUSION}

The data presented in the article shows that the oxidative desulfurization of various types of motor fuels is very effective and can be used as an independent method of deep desulfurization or as a logical addition to the large-scale hydro-treating process.

\section{Acknowledgment}

The research is performed with financial support of the Ministry of Education and Science of the Russian Federation under the agreement 14.577.21.0209, the unique identifier of the agreement is RFMEFI57716X0209.

\section{References}

[1] L.Sh. Makhmudova, Kh. Kh. Akhmadova, J.T. Khadisova, Zh.A. Abdulmezhidova, A.A. Pimenov, P.E. Krasnikov, "Production of lowfouling diesel fuels at Russian refineries: status and prospects", Ros.him. g. (J. Ros. Chemical Society. DI Mendeleev), no. 1, pp. 3-25, 2017.

[2] N.V. Borzenkova, I.A. Veselova, T.N. Shekhovtsova, "Biochemical methods for the desulfurization of hydrocarbon raw materials", Advances in modern biology, Vol.133, no. 1, pp.63-80, 2013.

[3] G. Mohebali, A.S. Ball, B. Rasekh, A. Kaytash, "Biodesulfurization Potential, Gordoniaalkanivorans RIPI90A”, Enz. Microb. Technol., vol. 40, no. 4, pp. 578-584, 2007.

[4] A.V. Anisimov, A.V. Tarakanova, "Oxidizing Desulfurization of Hydrocarbon Raw Materials", Russian Chemical Journal, vol. 5, no. 4, pp. 32-40, 2008.

[5] T.N. Mitusova, "Diesel, Marine, Boiler Fuel," World of Oil Products, no. 2, pp. 17-20, 2008.

[6] R.G. Galiev, B.N. Davydov, "Stimulating the production and use of ecological motor fuels by improving taxation", World of Oil Products, no. 2, pp. 39-45, 2008.

[7] Production of diesel fuel in Russia - results of 2016, Russian business magazine, http://www.rosbj.ru/2017/01/04/1239. 
[8] I.V. Pavlov, O.A. Druzhinin, V.A. Khavkin, L.A. Gulyaeva, N.Ya. Vinogradov, D.A. Mel'chakov, V.P. Tverdokhlebov, F.A. Buryukin, "Features of the technology of destructive hydrogenation processes in the production of low-fouling diesel fuels", World of Oil Products, no. 6, pp. 16-21, 2010

[9] Production and export of petroleum products, http://www.morvesti.ru/analytics/index.php?ELEMENT_ID=20117.

[10] O.B. Braginsky, N.N. Kunitsyna, A.V. Gorlov, "Rational Use of Hydrocarbons in the Oil and Gas Complex of Russia", Preprint WP, 2015/314, Moscow: CEMI RAS, p. 80, 2015

[11] Kh.E. Kharlampidi, "Organo-sulfur compounds of petroleum, methods of purification and modification", Soros Educational Journal, vol.6, no. 7, pp. 42-46, 2000.

[12] D.J. Monticello, "Biodesulfurization and upgrading of petroleum distillates", Cur. Opin. Biotechnol., vol. 11, no. 6, pp. 540-546, 2000.

[13] Zainutdinov K.R., A.A. Kuzhaeva, "Oxidative transformations of sulfur compounds of oil fractions", Proceedings of the XIV Youth International Scientific and Practical Conference of Students, Postgraduates and Young Scientists, pp.23-27, October 24-25, 2017, St. Petersburg, NorthCharleston, SC, USA: CreateSpace, [Step into the Future: Theoretical and Applied Studies of Modern Science, 2017].

[14] P.E. Krasnikov, Kh.H. Akhmadova, L.Sh. Makhmudova, Zh.T. Khadisova, Z.A. Abdulmezhidova, "Desulphurisation of diesel fuels using non-hydrogen technologies", Materials of the I International Scientific and Practical Conference dedicated to the 100th anniversary of them. Acad. Md Millionshchikov", vol.1, pp. 524-530, November 02-04, 2017 Russia, Chechen Republic, Grozny: FSBEI HE GGNTU, [Fundamental and applied research: problems and results, 2017].

[15] H. Shulz, W. Bohringer, P. Waller, F. Ousmanov, "Catal. Toda", vol. 49, No. 1-3, pp. 87-97, 1999.

[16] S. A. Loginov, V. M. Kapustin, A. I. Lugovskoy, K. B. Rudyak, "Improvement of the technological scheme and equipment for the production of high-quality diesel fuels", Refining and Petrochemicals, No. 8, pp. 11-13, 2001.

[17] A.V. Stavitskaya, "Development of methods for the oxidative modification of oil and products of its processing", Dis. Cand. tech. sciences. Moscow: Russian State University of Oil and Gas named after IM. Gubkina, vol.135, 2015.

[18] E. B. Krivtsov, "Transformations of sulfur compounds and aromatic hydrocarbons from diesel fractions of oils in oxidative desulfurization processes," Institute of Petroleum Chemistry, Siberian Branch of the Russian Academy of Sciences, Tomsk, p. 115, 2011.

[19] G.V. Tarakanov, A.R. Ramazanova, N.G. Ionov, V.P. Rudnev, "Refining Distillate Fractions and Residues of Oil and Gas Condensate Raw Materials," ASTU Bulletin, No. 2 (58), pp. 42-46, 2014

[20] K.B. Rudyak, "Modernization of technological schemes of oil refineries when changing requirements for the range and quality of products", Author, Moscow, p. 50, 2005.

[21] S.A. Loginov, B.L. Lebedev, V.M. Kapustin, A.I. Lugovskoy, V.M. Kurbanov, K.B. Rudyak, "Development of a New Technology for Hydrodesulfurization of Diesel Fuels", Refining and Petrochemicals, No. 11, p. 67-74, 2001.

[22] S.A. Loginov, V.M. Kapustin, A.I. Lugovskoy, K.B. Rudyak, B.L. Lebedev, "Industrial Production of High-Quality Diesel Fuels with a Sulfur Content of $0.035 \%$ and $0.05 \%$ ", Refining and Petrochemistry, No. 11, pp.52-61, 2001.

[23] A.A. Kuzhaeva, I.V. Berlin, "Methods of oxidative desulfurization of petroleum products", Problems of modern science and education, No. 9 (51), pp. 13-15, 2016.

[24] J. M. Campos-Martin, "Oxidative processes of desulfurization of liquid fuels", Journal of Chemical Technology \& Biotechnology, vol. 85, No. 7, pp. 879-890, 2010.

[25] G. Zhang, F. Yu., R. Wang, "Research advances in oxidative desulfurization of the production of low sulfur oils", Petroleum and Coal, vol. 51, No. 3, pp. 196-207, 2009.

[26] R.F. Galiev, V.R. Nigmatullin, R.G Nigmatullin, "Production of Diesel Fuel with Low Sulfur Content and Arenas", Refining and Petrochemistry. Scientific and Technical Achievements and Best Practices, No. 1, pp. 11-12, 2015.
[27] F.S. Mjalli, "Deepoxidativedesulfurizationofliquidfuels", Reviewsin Chemical Engineering, vol. 30, No. 4, pp. 337-378, 2014.

[28] Zh.T. Khadisova, E.A. Alexandrova, G.M. Naumova, "Group composition and properties of individual fractions of petroleum paraffin", Chemistry and technology of fuels and oils, No. 1, pp.47-49, 2005.

[29] R.R. Samatov, "Selective oxidation of petroleum sulphides with hydrogen peroxide to sulfoxides and sulfones", Ufa, 2007.

[30] A.E. Baymanova, G.ZH. Zhakupova, Sulfur-containing compounds of oil and the main methods of cleaning oil and oil fractions from them, Study Guide, 2010, p. 36.

[31] A.H. Sharipov, V.R. Nigmatullin, "Oxidative Desulfurization of Diesel Fuel (Review)”, Petrochemistry, vol.45, No. 6, pp.403-410, 2005.

[32] A.H. Sharipov, V.R. Nigmatullin, "Additional purification of diesel fuel from sulfur compounds after hydrotreating", Chemistry and Technology of Fuels and Oils, No. 4, pp. 42-44, 2005.

[33] A.V. Anisimov, V.T. Fam, A.V. Tarakanova, A.A. Seleznev, V.A. Chertkov, E.V. Rakhmanov, N.S. Kulikov, "Oxidation of organic sulfur compounds by hydrogen peroxide in the presence of crown ethers", Moscow University Bulletin, vol. 49, No. 1, pp. 58-65, 2008.

[34] E.V. Fedorov, N.P. Zhirkov, A.V. Tarakanova, A.A. Ivanov, V.M. Senyavin, A.V. Anisimov, E.V. Tulyakova, S.A. Surin, "Oxidative Desulfurization of Diesel Fuel by Hydrogen Peroxide in the Presence of Vanadium Peroxo Complexes," Petrochemistry, vol. 42, no. 4, pp. 282$286,2002$.

[35] A.Kh. Sharipov, "Oxidative Desulfurization of Diesel Fuel," Interval, No. 7, pp. 42-49, 2007.

[36] A.Kh. Sharipov, V.R. Nigmatullin, I.R. Nigmatullin, R.V. Zakirov, "Catalytic oxidation of sulfides of middle distillates of sour crude oil", Chemistry and technology of fuels and oils, no. 6, pp. 45-51, 2006

[37] E.V. Rakhmanov, D. Jinyuan, O.A. Fedorova, A.V. Tarakanova, AV Anisimov, "Oxidizing desulfurization of mixtures simulating diesel fuel with hydrogen peroxide using crown ethers and peroxocomplexes of transition metals", Petrochemistry, Vol. 51, No. 3, pp. 227-232, 2011

[38] A.V. Akopyan, "Oxidizing Desulfurization of Hydrocarbons by Hydrogen Peroxide in the Presence of Salts of Transition Metals", Moscow, p. 228, 2015.

[39] K.B. Krivtsova, E.B. Krivtsov, A.K. Golovko, "Removal of sulfur compounds from the diesel fraction by a combination of oxidation and extraction", News of Tomsk Polytechnic University. Engineering of georesources, vol. 319, No. 3, pp. 116-120, 2011.

[40] A.V. Anisimov, E.V., Fedorova, A.Z. Lesnugin, V.M. Senyavin, L.A. Aslanov, V.B. Rybakov, A.V. Tarakanova, Catal. Today, vol. 78, pp. 319-332, 2003

[41] V.T. Fam, A.V. Tarakanova, O.V. Kostyuchenko, B.N. Tarasovich, N.S Kulikov., A.V. Anisimov, "Oxidation of Organic Sulfur Compounds with Hydrogen Peroxide in the Presence of Niobium and Vanadium Peroxo Complexes", Chemical Technology, vol. 8, no. 12, pp. 537-543, 2007.

[42] J.M. Campos-Martin, G. Blanco-Brieva, J.L.G. Fierro, "Hydrogen peroxide synthesis: An outlook beyond the anthraquinone process," Angew. Chem. Int. Ed., Vol. 45, pp. 6962 - 6984, 2006.

[43] F.S. Mjalli, "Deep oxidative desulfurization of liquid fuels," Reviews in Chemical Engineering, vol. 30, No. 4, pp. 337-378, 2014

[44] P. De Filippis, M. Scarsella, "Oxidative Desulfurization: Sulfur Compounds in Different Organic Matrixes", Energy \& Fuels, vol. 17, No. 6 , pp. 1452-1455, 2003

[45] A.M. Dehkordi, M.A. Sobati, M.A. Nazem, "Oxidative Desulfurization of Non-hydrotreated Kerosene Using Hydrogen Peroxide and Acetic Acid", Chinese Journal of Chemical Engineering, vol. 17, No. 5, pp. 869-874, 2009.

[46] S. Otsuki et al., "Oxidation and Solvent Extraction, Energy \& Fuels", vol. 14, No. 6, pp. 1232-1239, 2000.

[47] P. De Fillipis, M. Scarsella, Energy and Fuel, vol. 17, No. 6, pp. 1452 1455,2003

[48] M.F. Ali, A. Al-Malki, A. El-Malki, B. El-Al., G. Martinie, M.N. Siddigui, "Fuel”, vol. 85, No. 10-11, pp. 1354-1363, 2006. 
[49] G.D. Halperin, "Heteroatomic Components of Oil", Advances in Chemistry, vol. 45, No. 8, p. 1395-1427, 1976

[50] T.F. KazumasaYazu, "TungstophosphoricAsid-catalyzed Oxidative Desulfurization of Light Peroxide in a Light Oil", Acetic Asid Biphasic System, Chemistry Letters, vol.32, No. 10, pp. 920-921, 2003.

[51] M. Al-Shahrani Farhan et.al, Catalytic process for deep oxidative desulfurization of liquid transportation fuels, US Patent 8663459 B 2, 2014.

[52] W. Trakarnpruk, K. Rujiraworawut, "Oxidative desulfurization of gas oil by polyoxometalates catalysts", Fuel Processing Technology, vol. 90, No. 3, pp. 411-414, 2009.

[53] F. Al-Shahrani, T. Xiao, S.A..Liewellyn, S.Barri, Z..Jiang, H.Shi, G. Martinie, M.L.H. Gree, Appl. Catal, B: Environmental, vol. 73, No. 3-4, pp. 311-316, 2007.

[54] F. Villasenor, O. Loera, A. Campero, G. Viniegra-Gonzalez, "Fuel Processing Technolology", vol. 86, No. 1, pp. 49-59, 2004

[55] L.C.Caero, E. Hernandez, F. Pedraza, F. Murrieta, Catal. Today, vol. 107-108, pp. 564-569, 2005

[56] L.C. Caero, F. Jorge, A. Navarro, A. Gutierrez-Alejandre, Catal. Today, vol. 116, No. 4, pp. 562-568, 2006.

[57] Fang Yunming, Hu Haoguan, Catalysis Commun, Vol. 8, No. 5, pp. 817-820, 2007

[58] J.T.Sampanthar, Xiao Huang, Dou Jian, Teo Yin Nah, Rong Xu, Pui Kwan Wong, Appl. Catal., B: Environmental, vol. 63, No. 1-2, pp. 8593, 2006.

[59] J.L. Garsia-Gutierrez, G.A. Fuentes, M.E., Hernandez-Teran, P. Garsia, F..Murrieta-Guevara, F. Jimenez-Cruz, Appl. Catal, A: General, vol.334, pp. 366-373, 2008.

[60] J.L. Garsia-Gutierrez, G.A. Fuentes, M.E., Hernandez-Teran, P. Garsia, F.Murrieta-Guevara, J. Navarrete, F. Jimenez-Cruz, Appl. Catal., A: General, vol. 305, No. 1, pp. 15-20, 2006.

[61] M.J. Da Silva, "Catalyst Model with AlPMo12O40 under Phase Transfer Catalyst - Free Conditions", Novel Oxidative Desulfurization of a Model Fuel with H2O2, Journal of Applied Chemistry, vol. 1, ID 147945, pp. 1-7, 2013.

[62] A.Kh. Sharipov, V.R. Nigmatullin, "Catalytic oxidation of sulfides of oil fractions with hydrogen peroxide", Petrochemicals, Vol. 45, No. 5, p. 351-354, 2005.

[63] R.R. Samatov, U.M. Dzhemilev, A.Kharipov, "Oxidation of sulphides of the diesel fraction of oil by hydrogen peroxide catalyzed by molybdenum compounds", Petrochemistry, Vol. 46, No. 6, p. 468-470, 2006.

[64] W. Trakarnpruk, K. Rujiraworawut, "Oxidative desulfurization of gas oil by polyoxometalates catalysts", Fuel Processing Technology, vol. 90, No. 3, pp.411-414, 2009.

[65] Fang Yunming, Hu Haoguan, "Catalysis Commun", vol. 8, No. 5, pp. 817-820, 2007.

[66] Kong Lingyan, Li Gang, Wang Xiangsheng, Wu Bo, Energy and Fuel, vol. 20, No. 3, pp. 896-902, 2006.

[67] Wang Yun, Li Gang, Wang Xiangsheng, Jin Changzi, Ibid, vol. 21, No. 3, pp. 1415-1419, 2007

[68] Patent \# 1715025, 2006

[69] S. Murata, K. Murata, K. Kidena, M. Nomura, Energy and Fuels, vol. 18, No. 1, pp. 116-121, 2004.

[70] V. Dumont, L. Oliviero, F. Mauge, M. Houalla, "Catal. Today, vol. 130, [94]
[71] T.V. Rao, B. Sain, S. Kafola, B.R. Nautiyal, Y.K. Sharma, S.M. Nanoti, M.O. Garg, Ibid, vol. 2, No. 6, pp. 3420-3424, 2007.

[72] Z. Jiang et al., "Oxidative Desulfurization of Fuel Oils", Chinese Journal of Catalysis, vol. 32, No. 5, pp. 707-715, 2011

[73] H. Lu, J. Gao, Z. Jiang, F. Jing, Y, Yang, G. Wang, C. Li, J Catal., Vol. 239, No. 2, pp. 369-375, 2006

[74] J. Gao, S. Wang, Z. Jiang, H. Lu, Y. Yang, F. Jing, C. J. Li, J Molec. Catal., A: Chem., Vol. 258, No. 1-2, pp. 261-266, 2006.

[75] J. Gao, S. Wang, Z. Jiang, H. Lu, Y. Yang, F. Jing, C. Li, J. Molec. Catal. A: Chem., Vol. 258, No. 1-2, pp. 261-266, 2006.

[76] C. Li et al., "Ultra-deep desulfurization of diesel: oxidation with a recoverable catalyst assembled in emulsion", Chemistry, vol. 10, No. 9, pp. 2277-2280, 2004.

[77] H. Lu et al., "Ultra-deep desulfurization of diesel selective selective oxidation with [C18H37N (CH3) 3] 4 [H2NaPW10O36] catalyst assembled in emulsion droplets", Journal of Catalysis, vol. 239, No. 2, pp. 369-375, 2006.

[78] H.R.D. Zhao, "Mechanism and Catalytic Behavior of Quaternary Ammonium Salts in Oxidative desulfurization", Petroleum Science and Technology, vol.27, pp. 1338-1348, 2009.

[79] F.M. Collins, A.R. Lucy, C. Sharp, "Oxidative desulphurization of oils and transoxides of catalysis", Journal of Molecular Catalysis A Chermical, vol.117, No. 1-3, pp. 397-403, 1979.

[80] T.O. Sachdeva, K.K. Pant, "Deep desulfurization of diesel via peroxide oxidation using phosphotungsticasid as phase transfer catalyst", Fuel Processing Technology, vol. 91, No. 9, pp. 1133-1138, 2010.

[81] Wu Xianxian, V. Shwartz, S.H. Overbury, T.R. Armstrong, Energy and Fuels, vol.19, No. 5, pp. 1774-1782, 2005.

[82] Yu Guoxian, Lu Shanxiang, Chen Hui, Zhu Zhongman, Ibid, vol. 19, No. 2, pp. 447-452, 2005.

[83] Yu Guoxian, Lu Shanxiang, Chen Hui, Zhu Zhongman, Carbon, vol. 43 , No. 11, pp. 2285-2294, 2005.

[84] J.T. Sampanthar, Xiao Huang, Dou, Jian Teo Yin Nah, Rong Xu, Pui Kwan Wong, Appl. Catal. B: Environmental, vol. 63, No. 1-2, pp. 85-93, 2006

[85] A.Kh. Sharipov, V.R. Nigmatullin, "Removal of sulfur from hydrotreated diesel fuel", Chemistry and Technology of Fuels and Oils, No. 3, p. 42-44, 2005.

[86] US patent number 60226049, 2006.

[87] Patent EP No. 1715025, 2006.

[88] C. Ma, A. Zhou, C. Song, Catal. Today, vol. 123, no. 1-4, pp. 276-284 2007

[89] F. Ishihara, et.al., "Oxidative desulfurization and denitrogenerationjf a light gas oil using an oxidation/adsorption continuous flow process", Applied Catalysis A: General, vol. 279, no.1-2, pp. 279-287, 2005.

[90] A. Chica, G.Gatti, B. Moden, L. Marchese, E.Iglesia, Chemistry - A European Journal, vol. 12, pp. 1960-1967, 2005.

[91] D.Wang, E.W. Qian, H. Amano, K Okata, A. Ishihara, T. Kabe, Appl. Catal. A: General, vol. 253, no. 1,pp. 91-99, 2003.

[92] S. Herbstmann, F. E. Guptill, "Desulfurization with a catalytic oxidation step", US Patent 3565793 A, 1971.

[93] J.S. Yoo, "Oxidation and desulfurization of a hydrocarbon materials", US Patent 3847798 A, 1974. 